\title{
Selection of Conditions of Ultrasound-Assisted, Three-Step Extraction of Ellagitannins from Selected Berry Fruit of the Rosaceae Family Using the Response Surface Methodology
}

\author{
Milczarek Agnieszka $^{1}$ (1) $\cdot$ Sójka Michał ${ }^{1} \cdot$ Klewicki Robert $^{1}$ \\ Received: 16 September 2019 / Accepted: 30 April 2020 / Published online: 2 June 2020 \\ (C) The Author(s) 2020
}

\begin{abstract}
The study examined the influence of the method of grinding the fruit—homogenisation and grinding using a cryogenic mill—on the extraction efficiency of the ellagitannins (ETs). Two methods of extraction support were compared: sonication and shaking. In the second stage, selection of the extraction with the best conditions was carried out using the response surface methodology (RSM). Ellagitannins were extracted in different variants of acetone concentration (40, 60, and 80\%), duration of sonication (5, 10 , and $15 \mathrm{~min})$, and temperature $\left(20,35\right.$, and $\left.50{ }^{\circ} \mathrm{C}\right)$. The extracts obtained were subjected to quantitative analysis by highperformance liquid chromatography with a diode-array detector (HPLC-DAD) and identification using a mass spectrometer. Grinding is an important stage in the extraction of ellagitannins from berries. Extracts from fruit shredded with a cryogenic mill were characterised by an average of $20 \%$ lower content of ellagitannins than extracts from homogenised fruit. Studies using RSM showed that the most important factor affecting the amount of extracted ellagitannins from all tested fruits is the concentration of acetone. The highest ETs concentration was obtained using $80 \%$ acetone solution (in the tested range 40-80\%). In the case of raspberries, strawberries, and wild strawberries, under the conditions used, the temperature and duration of sonication did not significantly affect the extraction efficiency. An interaction between extraction time and solvent concentration was observed for blackberries, indicating optimal conditions for this fruit as $15 \mathrm{~min}$ and an acetone concentration of $80 \%$, respectively.
\end{abstract}

Keywords Ellagitannins $\cdot$ Extraction $\cdot$ Homogenisation $\cdot$ Rosaceae $\cdot$ RSM

\section{Introduction}

In recent years, interest has been focused on ellagitannins (ETs), a group of compounds belonging to polyphenols (Rao et al. 2010; Feldman et al. 2003). ETs are monomeric and oligomeric hydrolysable tannins with a complex structure, whose mass ranges from 500 to $3000 \mathrm{Da}$ (Lekha and Lonsane 1997; Rao and Snyder 2010; Feldman et al. 2003; Niemetz and Gross 2005). One characteristic of ETs is the ester bond between the hexahydroxydiphenyl acid (HHDP) molecule and the saccharide, most commonly glucose (Lei et al. 2001). Hydrolysable tannins occur naturally in nature (Rao and Snyder 2010; Feldman et al. 2003). Plants of the Rosaceae family contain significant amounts of polyphenols

Milczarek Agnieszka

agnieszka.milczarek@p.lodz.pl

1 Institute of Food Technology and Analysis, Lodz University of Technology, ul. Stefanowskiego 4/10, 90-924 Lodz, Poland (including ETs) (Hakkinen \& Torronen, 2000). Due to the wide consumption, availability, and high economic importance of berries, they are the main source of ETs in the human diet (Rao and Snyder 2010; Perez-Jimenez et al. 2011).

The fruits of the Rosaceae family, which are characterised by a high content of ETs, comprise raspberry, blackberry, wild strawberry, and strawberry (Hager et al. 2008; Gasperotti et al. 2010; Kahkonen et al. 2012; Del Rio et al. 2010; Boyles and Wrolstad 1993; Wu and Prior 2005). In the fruit of raspberries and blackberries, characteristic ETs, which constitute up to $80 \%$ of their total content, are lambertianin $\mathrm{C}$ and sanguiin H-6 (Gasperotti et al. 2010; Beekwilder et al. 2005); while in strawberry and wild strawberry, this is agrimoniin (about 20$40 \%$ of total ETs) (Vrhovsek et al. 2012) (Fig. 1).

ETs have an anti-inflammatory effect, inhibit the growth of Helicobacter pylori, and reduce gastric ulcers (Enrico Sangiovanni et al. 2013). In addition, they show strong antioxidant properties, which is attributed to the large number of hydroxyl groups present in their structure (Kahkonen et al. 2012; Dias et al. 2015; Heinonen et al. 1998; Oszmiański and Wojdyło 2009). From the plum tree (Spondias mombin), 


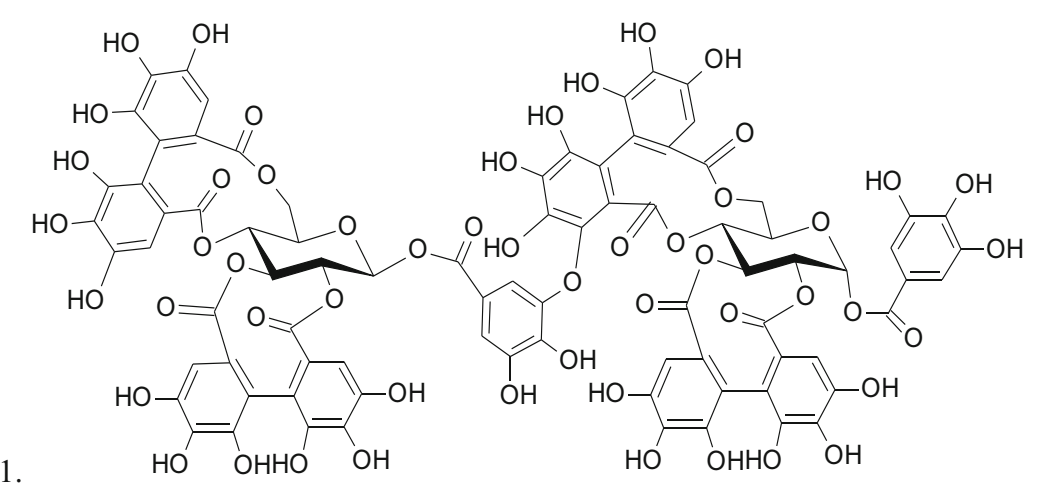

2.

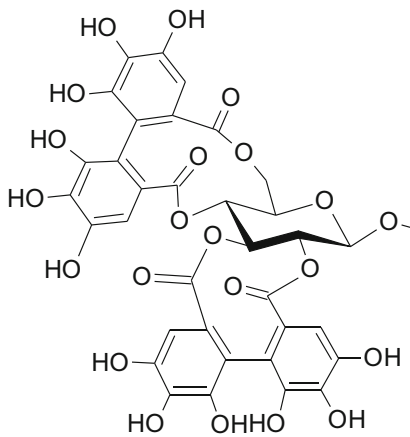

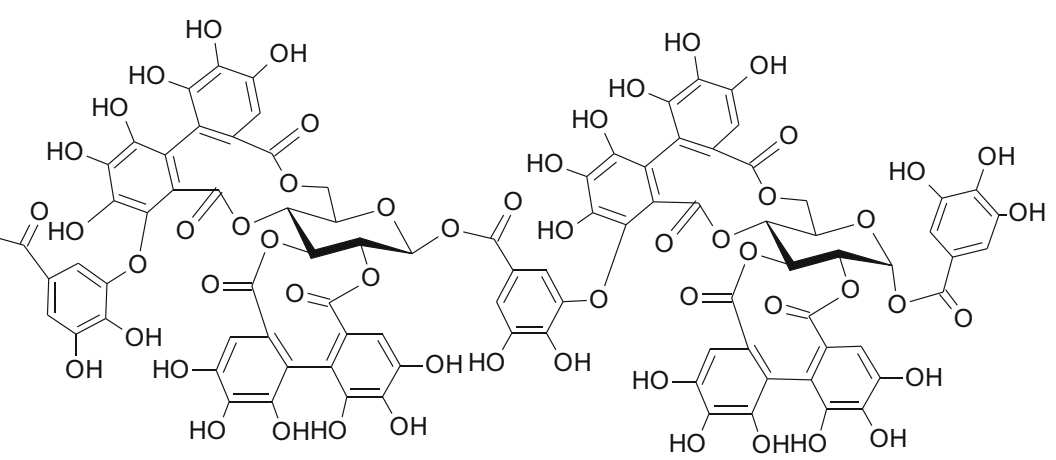

3.

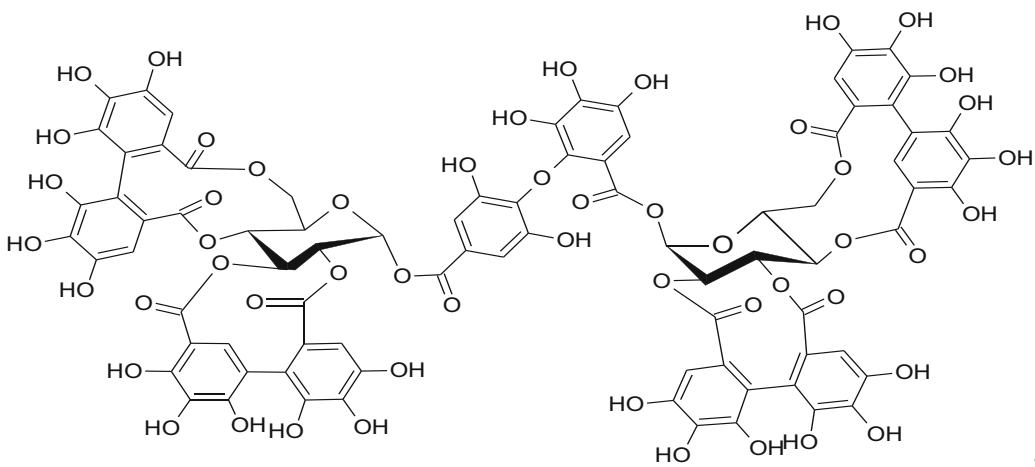<smiles>O=c1oc(=O)c2cc(O)c(O)c3c4oc(=O)c(c1cc(O)c4O)c23</smiles>

Fig. 1 The structure of the main ETs and ellagic acid of the Rosaceae fruit plants. (1) Sanguiin H-6. (2) Lambertianin C. (3) Agrimoniin. (4) Ellagic acid

an ET was isolated that exhibits antiviral activity against two viruses-Coxsackie and Herpes simplex (Corthout et al. 1991). It was also shown that the berries are anticancerous, thanks to their ability to stimulate apoptosis of colon cancer cells (Larrosa et al. 2010; Dai and Mumper 2010; Seeram et al. 2006) and inhibit cervical cancer cell proliferation (Ross et al. 2007). In addition, ETs have chelating properties, scavenge free radicals (thereby reducing oxidative stress), and they prevent chronic inflammation (Larrosa et al. 2006).

A large proportion of ellagitannins is closely related to the plant cell wall. This is mainly due to the ability of ETs to bind to basic compounds, high molecular weight compounds, proteins, metal ions, or pigment compounds (Okuda et al. 1992). Therefore, it is often impossible to make an accurate ETs assessment both quantitatively and qualitatively. It is important to correctly indicate the concentration of ellagitannins in fruits. Determining the exact ellagitannin profile will allow further research into their health-promoting effects. According to the literature, ETs were determined mainly on the basis of the amount of ellagic acid released during acid hydrolysis (Wada and Ou 2002; Siriwoharn and Wrolstad 2004; Klimczak and Król 2010).

Extraction is the first step on the path to quantitative and qualitative characterisation of the fruit profile of ellagitannins. Effective extraction of ETs from plant material is influenced by a number of factors, including temperature of extraction, use of supporting processes (e.g. sonication, shaking), and the degree of fragmentation of raw material (Galvan d'Alessandro et al. 2012). Extraction is supported by the use of ultrasound (Galvan d'Alessandro et al. 2012; Chandrapala et al. 2013). This technique is widely used in the extraction of polyphenolic compounds from plant material (Vilkhu et al. 2007; 
Baqueiro-Pena and Guerrero-Beltran 2017). Sonication causes mechanical disintegration of the cell wall (Guerrero et al. 2001; Bashi et al. 2012; Vilkhu et al. 2007). As a result, the contact area of the plant material with the solvent increases, which may promote increased extraction efficiency (Ma et al. 2008; Galvan d'Alessandro et al. 2012; Chandrapala et al. 2013). Analytical methods using ultrasound are environmentally friendly and are not very expensive (Khan et al. 2010).

For effective extraction, it is also important to select the right concentration of the extractant (Medina-Torres et al. 2017). The $\mathrm{pH}$ of the solvent has a significant influence on the extraction of polyphenols. It is advisable to use acidified solvents due to the denaturation of plant cell walls and higher polyphenol stability at low pH (Salminen 2003).

The RSM method is a hybrid of mathematics and statistics; it is an extremely precise tool for determining the relationship between the parameters studied and for studying the interactions that occur between them (Bezerra et al. 2008). The advantages of RSM and the Box-Benkhen tool include the fact that this method determines a reduced number of experiments to ascertain the interaction between many variables (Garcia-Marquez et al. 2012; Bezerra et al. 2008). Simultaneously, this method is less labor-intensive and time-consuming, and the results obtained are presented in a clear, transparent form. This method is increasingly used to determine dependencies in food (Lee et al. 2006).

To date, the selection of ETs extraction conditions from Rosaceae berries assisted with ultrasound has not been presented with the simultaneous use of the homogenisation process. Therefore, the purpose of the work was to indicate the significance of the initial treatment of the raw material as the first stage of preparing the fruit for extraction. An equally important aim was to determine the optimal parameters (time, temperature, acetone concentration) of ETs extraction from selected berries of the Rosaceae family.

\section{Materials and Methods}

\section{Fruits}

Four kinds of berry fruits of the Rosaceae family were selected for the study - raspberry (Rubus idaeus L.), garden blackberry (Rubus fruticosus L.), strawberry (Fragaria grandiflora), and wild strawberry (Fragaria vesca). These fruits are characterised by a varied, high content of ETs. Frozen fruit came from the Cajdex warehouse (Łódź, Poland). The fruit species have been identified by the supplier. Until the beginning of the tests, they were stored in tightly sealed polyethylene bags in a freezer at $-20^{\circ} \mathrm{C}$.

\section{Chemicals}

All reagents used for ETs extraction were of high purity. Solvents used for chromatography were of HPLC grade. Ultra-clean water was obtained with a Hydrolab-HLP5 demineraliser (Straszyn, Poland). Acetone (99.8\% purity) was purchased from Chempur (Piekary Ślaskie, Poland), acetonitrile (LC-MS grade) and phosphoric acid (85\% purity) from J.T. Baker (Deventer, The Netherlands), and formic acid from Sigma-Aldrich Chemie (Steinhem, Germany). Ellagic acid (> 95\% purity) was purchased from Extrasynthese (Genay, France).

Ellagitannin standards were used, which were obtained and purified (Sójka et al. 2016) at the Institute of Food Technology and Analysis of Lodz University of Technology. The standards were characterised by HPLC $(210 \mathrm{~nm})$. The purity of the standards was higher than $90 \%$.

\section{The Impact of the Grinding Process on the Extraction of Raspberry ETs}

Frozen raspberry fruit (ca. $50 \mathrm{~g}$ ) in liquid nitrogen (ca. 100 $\mathrm{mL}$ ) were ground with an IKA Basic cryogenic grinder (Staufen, Germany). Two gram portions of ground fruit were placed into $7-\mathrm{mL}$ polyethylene tubes, followed by a three-stage extraction process using a $60 \%$ aqueous acetone solution acidified with $0.1 \%$ formic acid. The extraction consisted of pouring into the weighed portion of fruit 3 $\mathrm{mL}$ of acidified acetone, sonication in an IS-4 ultrasonic bath with $950 \mathrm{~W}$ power (Olsztyn, Poland), or shaking in an IKA TSS 2 laboratory shaker at 150 RPM (Staufen, Germany). Subsequently, the samples were centrifuged for $15 \mathrm{~min}$ at $14000 \mathrm{~g}$ using an MPW-260R centrifuge (Warsaw, Poland). The obtained extract was decanted from the precipitate. The residue was subjected to the same extraction twice. The obtained extracts after three stages were dropped into one volumetric flask and filled up with an extractant to a volume of $10 \mathrm{~mL}$.

Extraction with the additional step of grinding was carried out in an analogous manner, with the difference that after the first sinking of the solvent from the sludge, the fruit was subjected to a 1-min homogenisation process at the fourth power level out of six available (using an IKA T10 basic homogeniser with a power of $125 \mathrm{~W}$ (Staufen, Germany).

List of Variants:

1. Sonication-assisted extraction (15 min) - SON

2. Sonication-assisted extraction (15 $\mathrm{min})$ with homogenisation of the sample (1 $\mathrm{min})-\mathrm{SON} / \mathrm{HOM}$

3. Extraction with shaking $(15 \mathrm{~min})-\mathrm{SH}$

4. Extraction with shaking (15 $\mathrm{min})$ with homogenisation of the sample $(1 \mathrm{~min})-\mathrm{SH} / \mathrm{HOM}$ 
Each variant was made in triplicate. The extracts obtained in this way were diluted 1:1 with mobile phase A and centrifuged at $12000 \mathrm{~g}$ in an MPW-260R centrifuge (Warsaw, Poland). The supernatant was placed in a chromatography vial and subjected to HPLC analysis.

\section{Selection of ETs Extraction Conditions with Response Surface Methodology}

In order to select conditions for the most effectice extraction, variant number 2 (extraction supported by sonication with homogenisation of the sample) was selected.

Liquid fruit samples frozen in liquid nitrogen were ground in an IKA Basic cryogenic mill (Staufen, Germany). The fruit was subjected to three-stage extraction with acetone assisted with sonication using an IS-4 ultrasonic bath (Olsztyn, Poland) (in the same way as in point 2.3). The parameters that were chosen are the concentration of aqueous acidified $(0.1 \%$ formic acid) extractant solution (acetone 40, 60, and 80\%), temperature $\left(20,35\right.$, and $\left.50{ }^{\circ} \mathrm{C}\right)$, and duration of sonication (5, 10, and $15 \mathrm{~min})$.

To select the best conditions for three-stage extraction of ETs, the RSM method was used with Statsoft Statistica (v. 7.0.61.0 EN). Independent variables, i.e. acetone concentration, temperature, and duration of sonication, were designated as $\mathrm{X} 1, \mathrm{X} 2$, and $\mathrm{X} 3$, respectively (Table 1). The dependent value - the answer-was the sum of the ellagitannins, i.e. the combined content of ellagitannins and ellagic acid [mg/ $100 \mathrm{~g}$ fresh weight (f.w.)]. The RSM test was designed on three levels using the Experimental Design Tool. The parameters were adjusted with the help of the Box-Benkhen design tool. The program matched 15 different experiments, of which

Table 1 Combinations of parameters - Box-Behnken design

\begin{tabular}{lll}
\hline Acetone concentration [\%] $X_{1}^{\mathrm{a}}$ & Time $[\mathrm{min}] X_{2}$ & Temperature $\left[{ }^{\circ} \mathrm{C}\right] X_{3}$ \\
\hline $40(-1)^{\mathrm{b}}$ & $5(-1)$ & $35(0)$ \\
$80(1)$ & $5(-1)$ & $35(0)$ \\
$40(-1)$ & $15(1)$ & $35(0)$ \\
$80(1)$ & $15(1)$ & $35(0)$ \\
$40(-1)$ & $10(0)$ & $20(-1)$ \\
$80(1)$ & $10(0)$ & $20(-1)$ \\
$40(-1)$ & $10(0)$ & $50(1)$ \\
$80(1)$ & $10(0)$ & $50(1)$ \\
$60(0)$ & $5(-1)$ & $20(-1)$ \\
$60(0)$ & $15(1)$ & $20(-1)$ \\
$60(0)$ & $5(-1)$ & $50(1)$ \\
$60(0)$ & $15(1)$ & $50(1)$ \\
$60(0)$ & $10(0)$ & $35(0)$ \\
$60(0)$ & $10(0)$ & $35(0)$ \\
$60(0)$ & $10(0)$ & $35(0)$ \\
\hline
\end{tabular}

${ }^{\mathrm{a}}$ Levels of factors, ${ }^{\mathrm{b}}$ Ranges of factors the first 12 related to the vertices of the studied area, while the last three included central values of independent variables. The experiments were performed three times, and the presented results are their average value.

The second-order polynomial model was used to analyse ET extracts. The analysis of the surface area of the response of independent factors $\left(X_{1}, X_{2}, X_{3}\right)$ on the efficiency of extraction measured with their concentration [mg/100 g f.w.] was determined by the equation:

$Y=\beta_{0}+\sum_{i=1}^{3} \beta_{i} X_{i}+\sum_{i}^{3} \beta_{i i} X_{i}^{2}+\sum_{i=1}^{2} \sum_{j=i+1}^{3} \beta_{i j} X_{i} Y_{j}$

where $\beta_{0}, \beta_{\mathrm{i}}, \beta_{\mathrm{ii}}, \beta_{\mathrm{ij}}$-regression coefficients, $X_{1}-X_{3}$-independent variables (temperature, time, acetone concentration).

The results were based on a statistical analysis of variance. Each parameter was tested, determining the probability at 0.05 . The measurement precision for the whole experiment was also determined based on repeatable centre points. The CV (coefficient of variance) was determined from the formula:

$\mathrm{CV}=\frac{\mathrm{SD}}{X^{\prime}} \times 100 \%$

where SD is the standard deviation, and $X^{\prime}$ is the average value for repeatable centre points.

\section{Analysis of Ellagitannins Content by HPLC}

Quantitative analysis was performed using a Smartline Knauer liquid chromatograph (Berlin, Germany). The set consisted of a degasser (Manager 5000), two pumps (P1000), a PDA detector (2800), an autosampler (3950), and a thermostat. Gemini C18 110 A columns with dimensions of $250 \mathrm{~nm} \times 4.6 \mathrm{~mm}, 5 \mu \mathrm{m}$ (Phenomenex, Torrance, CA) were used for the separation of the ETs. The flow rate was $1.25 \mathrm{~mL} /$ min and the injection volume was $20 \mu \mathrm{L}$. The column temperature was $35^{\circ} \mathrm{C}$. A PDA detector with a wavelength of $250 \mathrm{~nm}$ was used. The distribution proceeded in a gradient system with the following phases: phase $\mathrm{A}-0.05 \%$ aqueous phosphoric acid and phase B-aqueous solution of $83 \%$ acetonitrile acidified with $0.05 \%$ phosphoric acid solution. The proportion of phases in the gradient was as follows: 0-5 min $5 \%$ phase $\mathrm{B}, 95 \%$ phase $\mathrm{A} ; 5-10 \mathrm{~min}-5-15 \%$ phase $\mathrm{B}, 95-$ 85 phase $A ; 10-35$ min - $15-40 \%$ phase $B, 85$ - 60 phase $A$; 35-40 min - 40-73\% phase B, 60 - 27\% phase A; 40-44 min $73 \%$ phase B, $27 \%$ phase A; $44-46$ min - $73-5 \%$ phase B, 27-95\% phase A; and 46-54 min - 5\% phase B, 95\% phase A.

Standard curves were constructed for ellagic acid, lambertianin $\mathrm{C}$, sanguiin $\mathrm{H}-6$, and agrimoniin (in the range of $0.5-300,0.5-225,0.5-200$, and $0.5-100 \mathrm{mg} / \mathrm{L}$, respectively). The concentration of lambertianin $\mathrm{D}$ was calculated on the basis of the lambertianin $\mathrm{C}$ standard curve, the concentration 
of sanguiin H-10 and unidentified ETs on the basis of the sanguiin H-6 curve, and the concentration of derivatives and ellagic conjugates on the basis of the ellagic acid curve. The main validation parameters, i.e. LOD (limit of detection) and LOQ (limit of quantification), were determined on the basis of standard curve equations. LOD was the $b$ factor. LOQ was calculated by multiplying the LOD three times (Table 2).

Data were collected using ClarityChrom v. 3.0.5.505 (Berlin, Germany).

\section{Identification of ETs}

The ETs were identified in accordance with the methodology described by Sójka et al. (2016). Samples for LC-MS analysis were extracted under medium conditions, i.e. $60 \%$ acidified acetone solution, temperature $35{ }^{\circ} \mathrm{C}$, and duration of sonication $10 \mathrm{~min}$. Extraction was carried out three times.

The separation of ETs was carried out using a HPLC chromatograph (Dionex Ultimate 3000) coupled to a DAD detector and a Q Exactive Orbitrap mass spectrometer (Thermo Fisher Scientific, Waltham, MA).

For the chromatographic separation, Luna C18 $100 \AA$ column with dimensions $250 \mathrm{~mm} \times 4.6 \mathrm{~mm}, 5 \mu \mathrm{m}$ (Phenomenex, Torrance, CA) was used. The column was thermostatically regulated at $35^{\circ} \mathrm{C}$. The injection volume was $20 \mu \mathrm{L}$, and the flow rate was set to $1 \mathrm{~mL} / \mathrm{min}$. The following mobile phases were used: $\mathrm{A}-1 \%$ aqueous formic acid solution; $\mathrm{B}-80 \%$ aqueous acetonitrile solution. The determination was made in a concentration gradient with the following characteristics of the phase participation: $0-6.5 \mathrm{~min}-5 \%$ phase B, $95 \%$ phase A; 6.5-12.5 min - 5 - 15\% phase B, 95 - $85 \%$ phase A; $12.5-$ 44 min - 15 - $45 \%$ phase B, 85 - $55 \%$ phase A; $44-45$ min 45-75\% phase B, 55 - 25\% phase A; 45-50 min - 75\% phase $\mathrm{B}, 25 \%$ phase $\mathrm{A} ; 50-52 \mathrm{~min}-75-5 \%$ phase $\mathrm{B}, 25-95 \%$ phase A; 52-65.5 min - 5\% phase B, $95 \%$ phase A.

The mass spectrometer was equipped with a heated electrospray ion source operating in a negative mode. Mass spectrometer parameters were set as follows: capillary temperature $-400{ }^{\circ} \mathrm{C}$, ionic sputtering voltage $-4 \mathrm{kV}$, and evaporator temperature $-500{ }^{\circ} \mathrm{C}$. The sheath and auxiliary gas flows were 75 and 20 units, respectively. The detector worked in Full MS mode and in full scan mode MS/dd-MS ${ }^{2}$
(MS with data-dependent tandem mass spectrometry). In the MS full scan mode, the mass range was set to 200-2000. In the MS/dd-MS ${ }^{2}$ scanning mode, the product's ionic spectra were obtained. For this purpose, the collision energy needed to generate the $\mathrm{MS}^{2}$ spectra was set to 20 .

The results were collected using Xcalibur (Thermo) software.

\section{Results and Discussion}

\section{Identification of ETs from Selected Berry Fruit of the Rosaceae Family}

Table 3 shows the identification of the main ETs present in the tested fruits. According to the literature, in the case of raspberry and blackberry, the dominant ETs are lambertianin $\mathrm{C}$ and sanguiin H-6 (peaks 6 and 7) (Fig. 2) (Gasperotti et al. 2010; Mullen et al. 2002). In both fruits, there was also a conjugate of ellagic acid with pentose (peak 8) (Gasperotti et al. 2010). The difference in mass (433-301) indicates the possibility of pentose (Gasperotti et al. 2010). In addition, lambertianin D (peak 4) also appeared in the blackberry (Tanaka et al. 1993). A double-charged main ion at $m / z$ 1401 with a simultaneous triple ion $\mathrm{m} / \mathrm{z}, 934.07$ was identified as lambertianin C (Gasperotti et al. 2010; Sójka et al. 2016). The fragmentation ion $\mathrm{m} / \mathrm{z} 1567.15$ derived from the detachment of the rest of HHDP (1869-302). Further fragmentation indicates the detachment of further HHDP residues or glucosyl residues (Mullen et al. 2002). Numerous reports confirm that sanguiin H-6 and lambertianin $\mathrm{C}$ are characteristic ellagitannins for raspberry and blackberry (Tanaka et al. 1993; Mullen et al. 2002; Sójka et al. 2016; Hager et al. 2008).

Agrimoniin was identified in strawberry and wild strawberry (peak 9) (Vrhovsek et al. 2012). As unknown, ET was also identified in wild strawberry (peak 1). This compound has already been indicated as an unknown ellagic acid trimer derivative (Bubba et al. 2012).

Lambertianin $\mathrm{C}$ and sanguiin H-6 have also been detected in strawberry (Mullen et al. 2002). However, in the polyphenolic profile of the fruits studied in this work (strawberry, wild strawberry), there were no mass peaks corresponding to these

Table 2 Analytical parameters used for quantitative analysis of ellagitannins

\begin{tabular}{llllll}
\hline ET & Linear range $[\mathrm{mg} / \mathrm{L}]$ & $R^{2}$ & LODa $[\mathrm{mg} / \mathrm{L}]$ & LOQ $^{\mathrm{b}}[\mathrm{mg} / \mathrm{L}]$ & System \\
\hline LC $^{\mathrm{c}}$ & $0.5-225$ & 0.999 & 0.4 & 1.3 & Smartline Knauer liquid chromatograph, column: Gemini C18 110A \\
SH-6 $^{\mathrm{d}}$ & $0.5-200$ & 0.999 & 0.3 & 1.0 & $(250 \mathrm{~nm} \times 4.6 \mathrm{~nm}, 5 \mu \mathrm{m}), \lambda=250 \mathrm{~nm}, t=35^{\circ} \mathrm{C}$ \\
$\mathrm{EA}^{\mathrm{e}}$ & $0.5-300$ & 0.998 & 0.2 & 1.3 \\
$\mathrm{AGR}^{\mathrm{f}}$ & $0.5-100$ & 0.998 & 0.4 & & \\
\hline
\end{tabular}

${ }^{\mathrm{a}}$ Limit of detection, ${ }^{\mathrm{b}}$ Limit of quantification, ${ }^{\mathrm{c}}$ Lambertianin $\mathrm{C},{ }^{\mathrm{d}}$ Sanguiin $\mathrm{H}-6,{ }^{\mathrm{e}}$ Ellagic acid, ${ }^{\mathrm{f}}$ Agrimoniin 


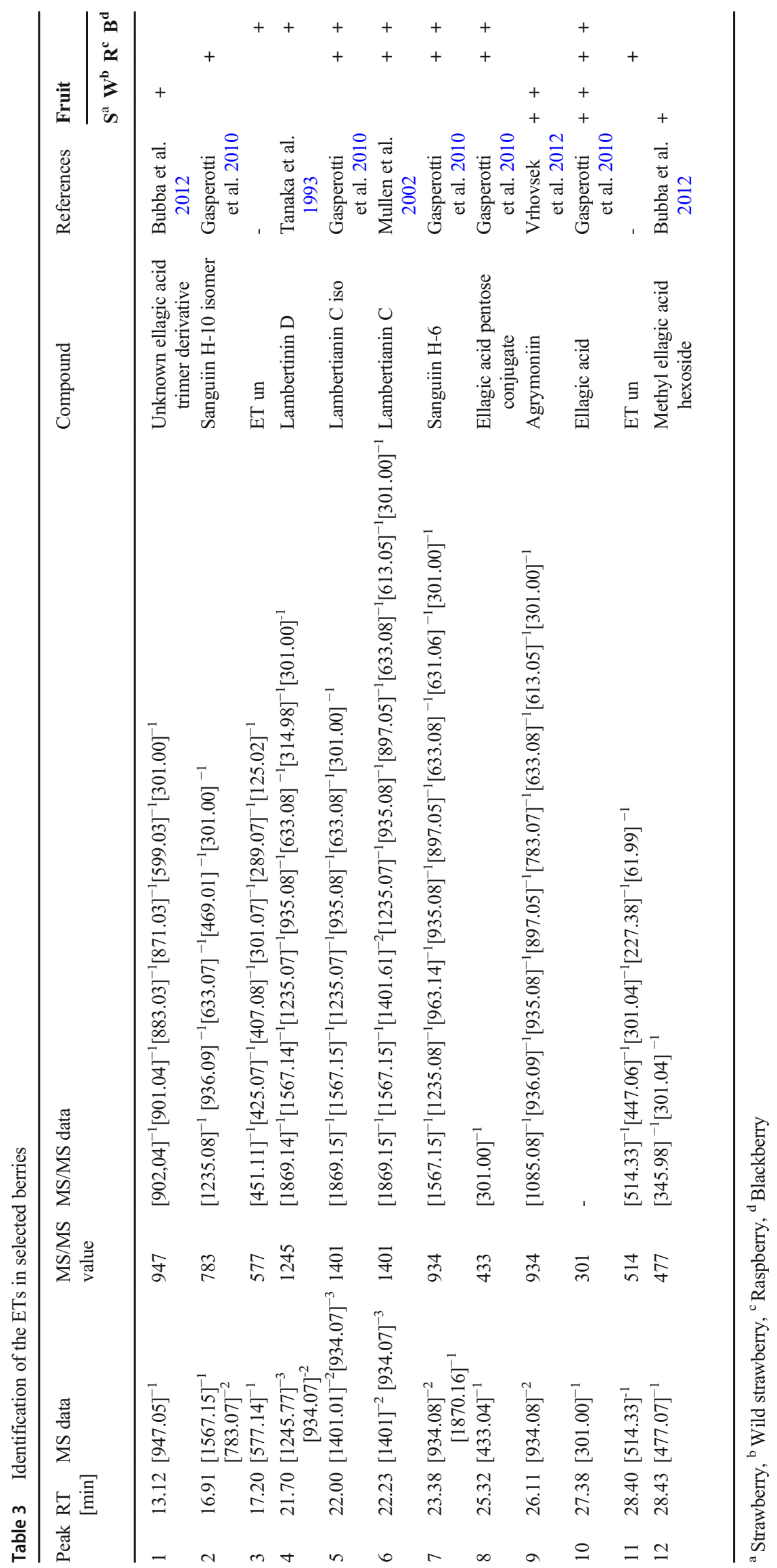




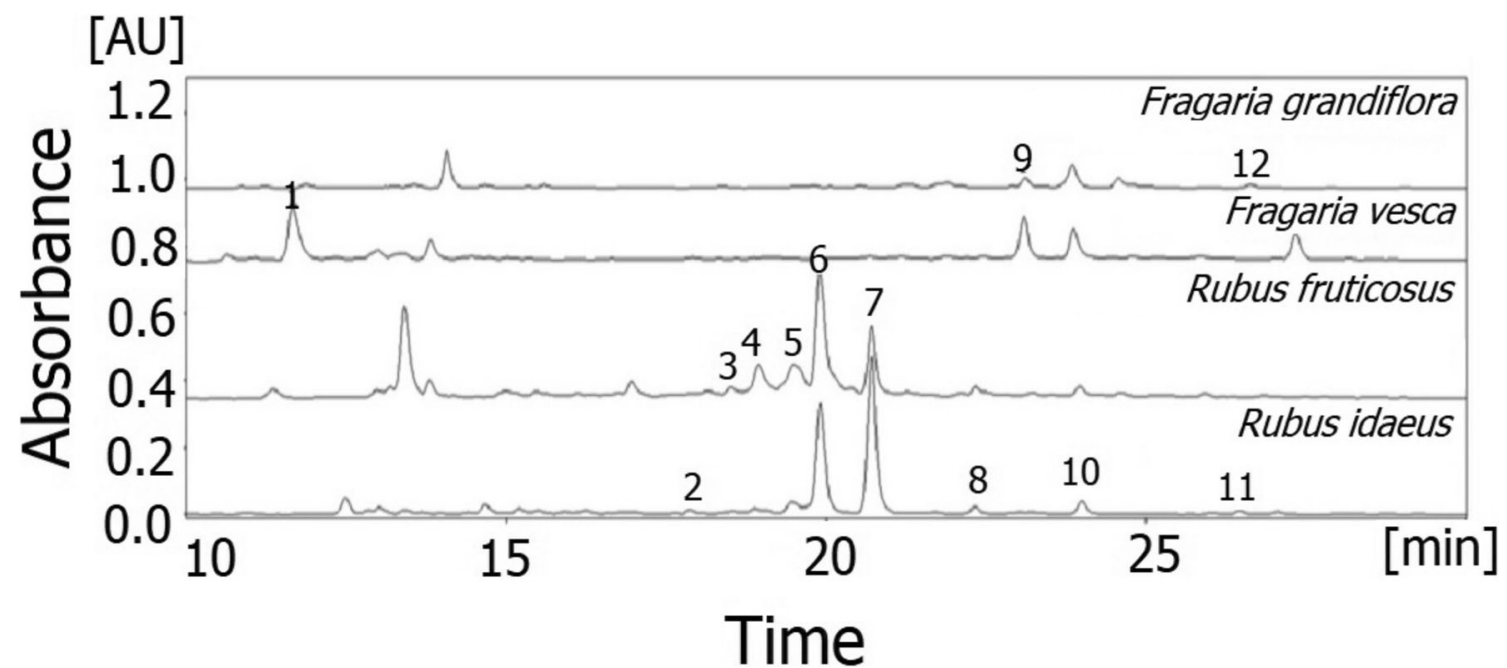

Fig. 2 Chromatogram of ellagitannins in selected berry fruits (Smartline Knauer liquid chromatograph, column: Gemini C18 $110 \mathrm{~A}, 250 \mathrm{~nm} \times 4.6 \mathrm{~nm}, 5$ $\mu \mathrm{m}, \lambda=250 \mathrm{~nm}, t=35^{\circ} \mathrm{C}$ )

compounds. The presence of sanguiin H-6 in strawberry may result from the lack of unambiguous identification of the structure of agrimoniin (Vrhovsek et al. 2012).

The spectra of sanguiin H-6 and agrimoniin are very similar to each other because these compounds are composed of the same monomers. In the case of sanguiin H-6, in addition to $\mathrm{m} / \mathrm{z} 934.08$ (characteristic for both compounds), there is also a peak at $\mathrm{m} / \mathrm{z}, 1870.16$. The literature reports that sometimes in the spectrum of agrimoniin, it is also possible to observe this peak (Vrhovsek et al. 2012). For correct identification, an accurate analysis of the ion fragmentation is indicated. The low intensity ion at $\mathrm{m} / \mathrm{z}, 1567.15$ occurs in a typical mass decay for sanguiin H-6 (Gasperotti et al. 2010). The weight of 1567.15 comes from the loss of one HHDP residue followed by the transfer of $2 \mathrm{H}$ to glucose. The HHDP unit is then transformed to ellagic acid, giving a mass $\mathrm{m} / \mathrm{z}$ 301.00, which is characteristic for the ETs (Gasperotti et al. 2010). Agrimoniin is characterised by a different profile of mass decay (Vrhovsek et al. 2012). The literature distinguishes between agrimoniin and sanguiin H-6 on the basis of a different retention times (26.11 min for agrimoniin). Agrimoniin elutes at a later time during the gradient due to the fact that its polarity is lower. This compound was identified in strawberry and wild strawberry as the primary ellagitannin (peak 8) (Vrhovsek et al. 2012). The occurrence of agrimoniin in strawberry and wild strawberry was confirmed earlier, but its structure was clearly defined in 2012 (Vrhovsek et al. 2012). The occurrence of three isomers of agrimoniin in strawberry leaves (Okuda and Ito 2011) was also indicated.

Sanguiin H-10 isomer (peak 2) was also recognised in raspberry, for which the retention time was $16.91 \mathrm{~min}$. In the mass spectrum, the dominant peak was $m / z$ 783.07. Such a mass distribution is also found for bis-HHDP-glucose; however, the characteristic for sanguiin H-10 is a double-charged fragment $\mathrm{m} / \mathrm{z}$ 783.07, which gives a mass of 1557.15 (Tanaka et al. 1993).
The ellagic acid was identified in all the tested fruits of the Rosaceae family, which is consistent with the literature (Mullen et al. 2002; Hager et al. 2008; Sójka et al. 2016; Bubba et al. 2012).

\section{The Impact of the Grinding Process on ETs Extraction}

The values of total ETs concentrations for different extraction methods were determined based on one-way ANOVA analysis and post-hoc Duncan tests. Raspberry was chosen for the study of the impact of the grinding process on the extraction of ETs because it is a fruit with a well-understood composition of ETs (both quantitative and qualitative) (Sójka et al. 2016). The homogenisation process significantly supports the extraction of ETs from raspberry fruit (Fig. 3). The total content of ETs from fruit further minced with a homogeniser increases on average by more than $20 \%$. During the extraction of fruit chopped only in a cryogenic mill, $145 \mathrm{mg}$ of ellagitannins were extracted from $100 \mathrm{~g}$ of fruit, while additional

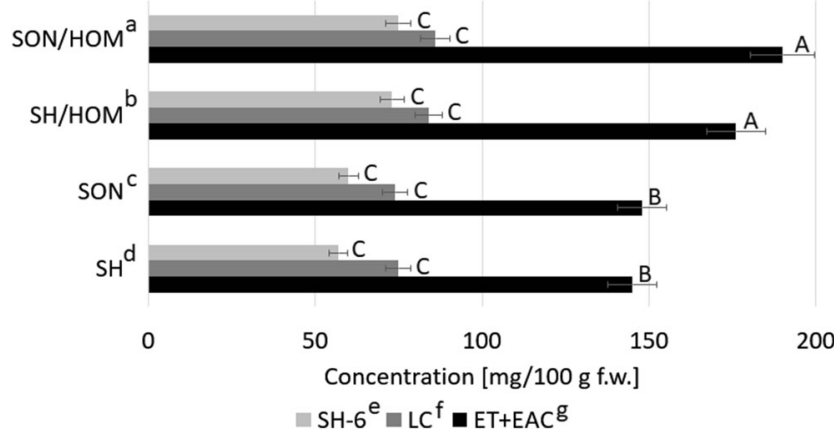

Fig. 3 Comparison of the influence of extraction aids and homogenisation methods on the content of ETs in raspberry fruit, ahomogenisation + sonication, ${ }^{\mathrm{b}}$ homogenisation + shaking, ${ }^{\mathrm{c}}$ sonication, ${ }^{d}$ shaking, ${ }^{e}$ sanguiin H-6 ${ }^{\mathrm{f}}$ lambertianin C, ${ }^{\mathrm{g}}$ total content of ETs with ellagic acid and conjugates; the results marked with the same roman letter do not differ statistically $(\mathrm{p}<0.05)$ 
Fig. 4 Photographs of fruit after grinding in liquid nitrogen (LN) and after additional homogenisation ( $\mathrm{LN}+\mathrm{HOM})$; R raspberry, B blackberry, S strawberry, WS wild stawberry
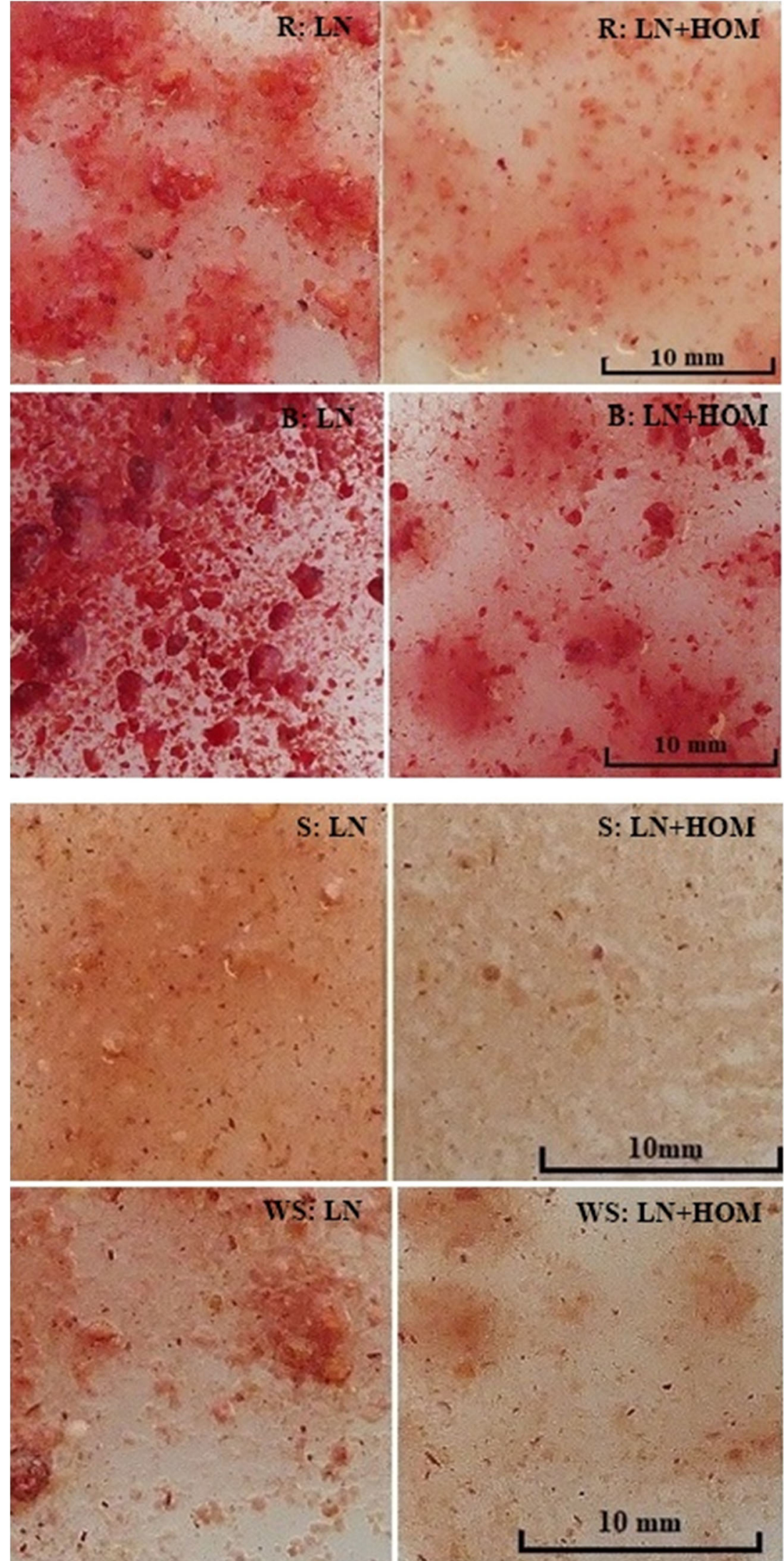
homogenisation increased this to $190 \mathrm{mg}$ from $100 \mathrm{~g}$ of fruit. This is largely due to the fact that the homogeniser mechanically crushes the seeds and degrades the cell wall (Popko 1981). According to a study by Klimczak, $18 \%$ of the ellagic acid released during the hydrolysis is in the strawberry seeds, $38 \%$ in the pulp, and $44 \%$ in the juice (Klimczak et al. 2011). The milling of raspberries only in a cryogenic mill is therefore not a sufficient process to effectively isolate the ETs from the plant matrix. The particle size depending on the grinding method is shown in Fig. 4.

Fragmentation of plant tissue increases the contact area between plant material and solvent (Popko 1981; Galvan d'Alessandro et al. 2012). This is confirmed by research on the extraction of polyphenols from blueberries; the highest efficiency of phenolic compound extraction is obtained for particles with diameter smaller than $0.5 \mathrm{~mm}$ (Galvan d'Alessandro et al. 2012). The results obtained by Galvan indicate that a 4-h extraction at $50{ }^{\circ} \mathrm{C}$ (without sonication) of finely divided particles $(<0.5 \mathrm{~mm})$ allows results similar to those obtained using ultrasound-assisted extraction for halfcut berries to be obtained (Galvan d'Alessandro et al. 2012). Galvan d'Alessandro et al. (2012) also emphasises the importance of supporting sonication extraction due to its simultaneous shortening of the whole process; $15 \mathrm{~min}$ of sonication allowed a higher process efficiency to be obtained compared to $1 \mathrm{~h}$ of extraction without support.

The studies also compared the process of shaking and sonication as the main elements supporting extraction of ellagitannins from raspberry fruit. In both cases, the values of extracted ETs range from 145 to $148 \mathrm{mg} / 100 \mathrm{~g}$ f.w., which are comparable values. A higher concentration of extracted ETs was observed for sonication plus homogenisation. Therefore, the sonication and homogenisation processes were tested.

\section{Results of Ellagitannins Extraction Analysis}

Further studies for all the analysed fruits were carried out using an additional homogenisation process, due to the higher extraction efficiency of the ellagitannins. Extraction was supported by the sonication process. The values of ellagitannin concentrations for individual factors were determined based on one-way ANOVA analysis and post-hoc Duncan tests.

\section{Effect of Solvent Concentration}

The literature suggests that using acetone concentrations of 60-70\% can achieve a much higher polyphenol content in the extract compared to lower or higher acetone concentrations (Salminen 2003). So far, it has been established that the most efficient solvent used to extract ellagitannins is a $70 \%$ acidified acetone solution (Salminen 2003; Klimczak and Król 2010). The two main ellagitannins, lambertianin C and sanguiin H-6, exhibit stability in acidic solutions ( $\mathrm{pH} 2$ and 4) (Sójka et al. 2019). Therefore, the tests were carried out in three different concentrations of acidified acetone, i.e. 40 , 60 , and $80 \%$.

Studies carried out as part of the work clearly indicate that for the effective extraction of the ETs from the tested fruits of the Rosaceae family, the best concentration of acetone in the examined scope was $80 \%$. For blackberry, wild strawberry, and strawberry, extracts with the highest concentration of ellagitannins were obtained using an acidified $80 \%$ acetone solution (Fig. 5). When using $80 \%$ acetone, 120, 55, and $270 \mathrm{mg}$ of ETs were extracted from $100 \mathrm{~g}$ of wild strawberry, strawberry, and blackberry, respectively. In the case of raspberry, the total sum of ETs was 245,290 , and $285 \mathrm{mg} / 100 \mathrm{~g}$, respectively, using acetone concentrations of 40,60 , and $80 \%$, respectively.

Lower ET values were obtained using lower concentrations of acetone (40 and $60 \%): 110 \mathrm{mg} / 100 \mathrm{~g}$ for wild strawberry and $45 \mathrm{mg} / 100 \mathrm{~g}$ for strawberry. Similar results were obtained by da Silva Pinto et al. (2008) who also extracted the most tannins hydrolysable from strawberry using $80 \%$ acetone. A similar relationship was observed in the presented studies, e.g. for blackberry - the acetone with the highest concentration extracted $270 \mathrm{mg}$ ETs per $100 \mathrm{~g}$ of fruit, while in the lowest, extracted $250 \mathrm{mg}$ per $100 \mathrm{~g}$.
Fig. 5 The effect of extraction conditions on the amount of ETs extracted, the results marked with the same roman letter do not differ statistically $(\mathrm{p}<0.05)$

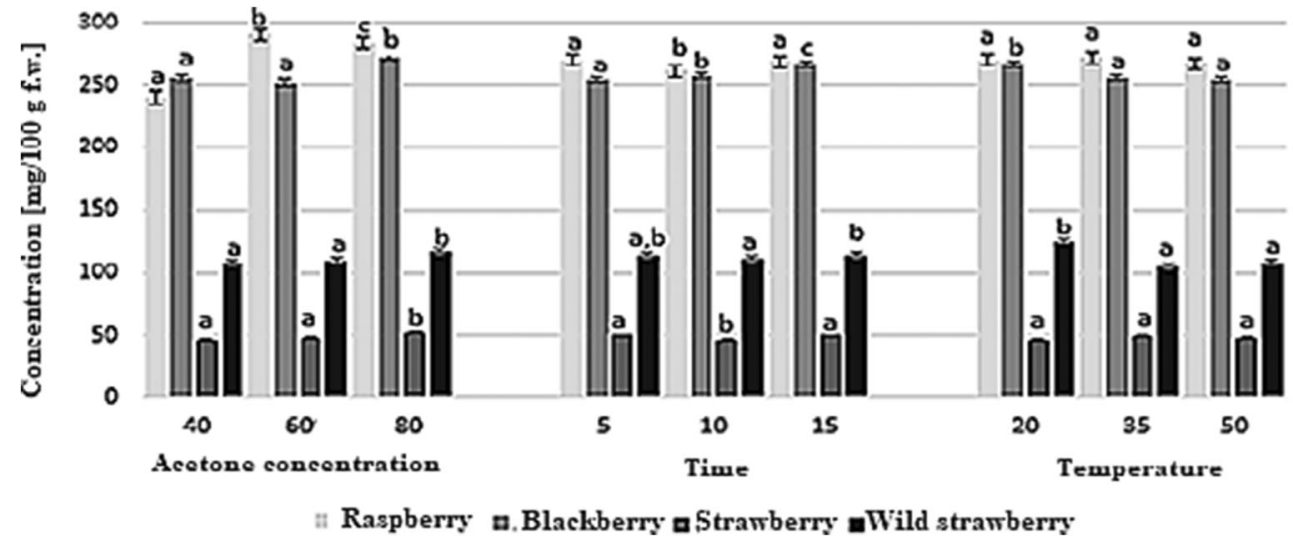



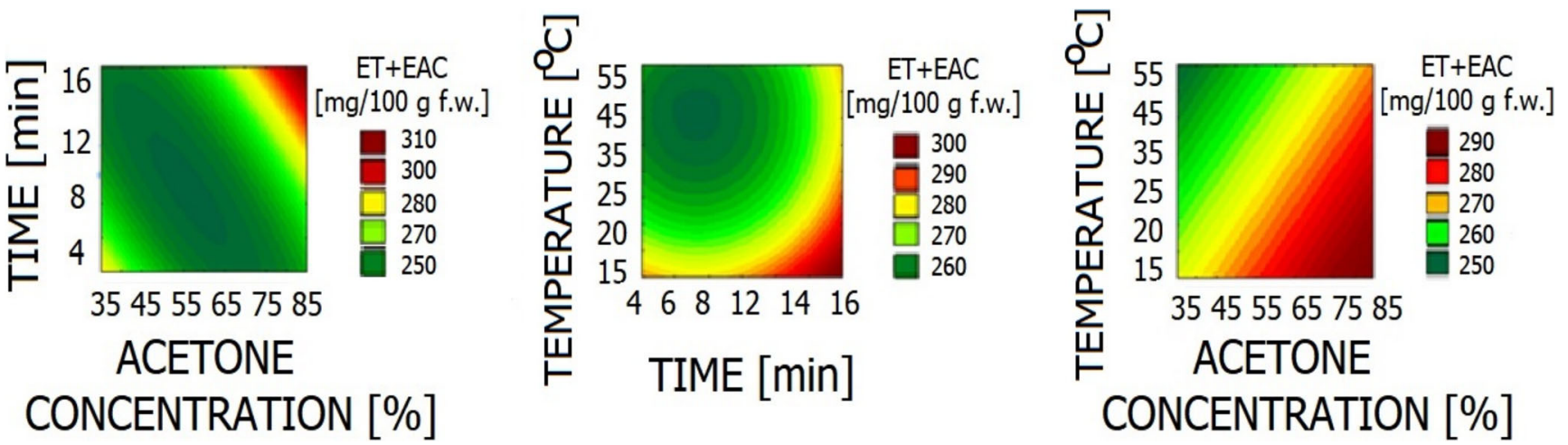

Fig. 6 Plane response plots - dependencies between tested parameters and sum of ETs from blackberry fruit

Too low a concentration of acetone means higher water content, which is not conducive to extraction efficiency (Salminen 2003). By the addition of water with high polarity, the polarity of moderately polar solvents gradually changes. This in turn affects the ability to extract polyphenols (Chirinos et al. 2007; Zhang et al. 2007; Liu et al. 2000). A higher proportion of water favors the extraction of other compounds, such as sugars or proteins (Chirinos et al. 2007).

\section{The Influence of Temperature}

ETs are polyphenols that degrade much faster at temperatures of $60-80{ }^{\circ} \mathrm{C}$ (Sójka et al. 2019; Chira and Teissedre 2013); therefore, for the present research, the temperature range of $20-50{ }^{\circ} \mathrm{C}$ was tested. In addition, the use of temperatures greater than $50^{\circ} \mathrm{C}$ may involve the risk of acetone evaporation (the boiling point of acetone is $56^{\circ} \mathrm{C}$ ), which changes the efficiency of extraction (Garcia-Marquez et al. 2012). The presented studies confirm this relationship; for selected fruits of the Rosaceae family (i.e. blackberry, raspberry, strawberry, wild strawberry), the highest ETs concentration in the extracts was recorded when conducting the process at $20^{\circ} \mathrm{C}$ (Fig. 5). In the case of raspberry and strawberry, the increase in temperature did not cause an unambiguous increase in the ellagitannins - the values of the extracted ETs in each of the tested temperatures were similar and amounted, respectively, to 270 and $45 \mathrm{mg} / 100 \mathrm{~g}$ f.w. The difference is observed in the case of blackberry and wild strawberry, where the increase in temperature caused a decrease in ETs concentration. In the case of wild strawberry, the value of ETs at $20{ }^{\circ} \mathrm{C}$ was 125 $\mathrm{mg} / 100 \mathrm{~g}$, and at higher temperatures- $110 \mathrm{mg} / 100 \mathrm{~g}$, whereas analysing the extracts from blackberry at $20^{\circ} \mathrm{C}$ and higher, respectively, 265 and $250 \mathrm{mg} / 100 \mathrm{~g}$.

The literature indicates that increasing the temperature (> $25^{\circ} \mathrm{C}$ ) of extraction may favor the degradation of phenolic moieties and hydroxyl groups in certain polyphenol groups. Interestingly, even those polyphenols that are associated with the fruit matrix can undergo degradation (Akowuah et al. 2009; Davidov-Pardo et al. 2011). On the other hand, this degradation depends largely on the structure of the extracted compounds. In the literature, it was pointed out that the gentle heating of the material to be extracted may favor the change in the properties of plant cells and hence the increased release of polyphenols from fruits (Akowuah et al. 2009).

\section{Duration of Sonication}

Sonication contributes to increasing the area of contact of the plant tissue with the solvent. This is due to the formation of bubbles inside the plant cells. Implosion of the bubbles - cavitation-generates a local increase in temperature and pressure (Japon-Lujan et al. 2006). In research, Klimczak and Król (2010) compiled the length of extraction time with the amount of ellagic acid released during hydrolysis. To obtain the greatest
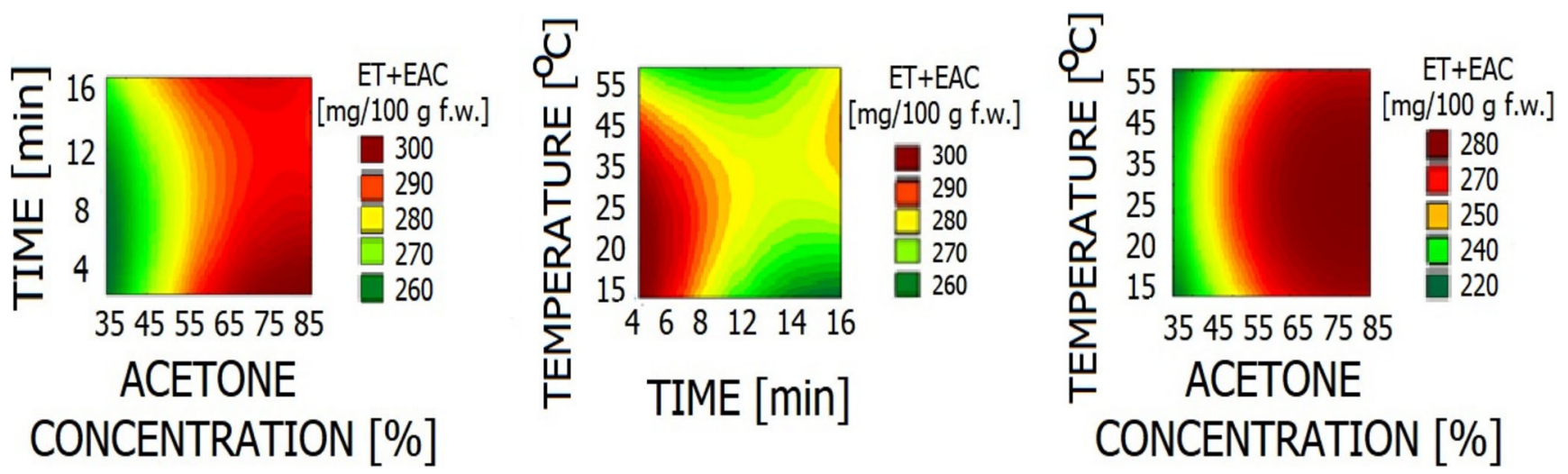

Fig. 7 Plane response plots - dependencies between tested parameters and sum of ETs from raspberry fruit 


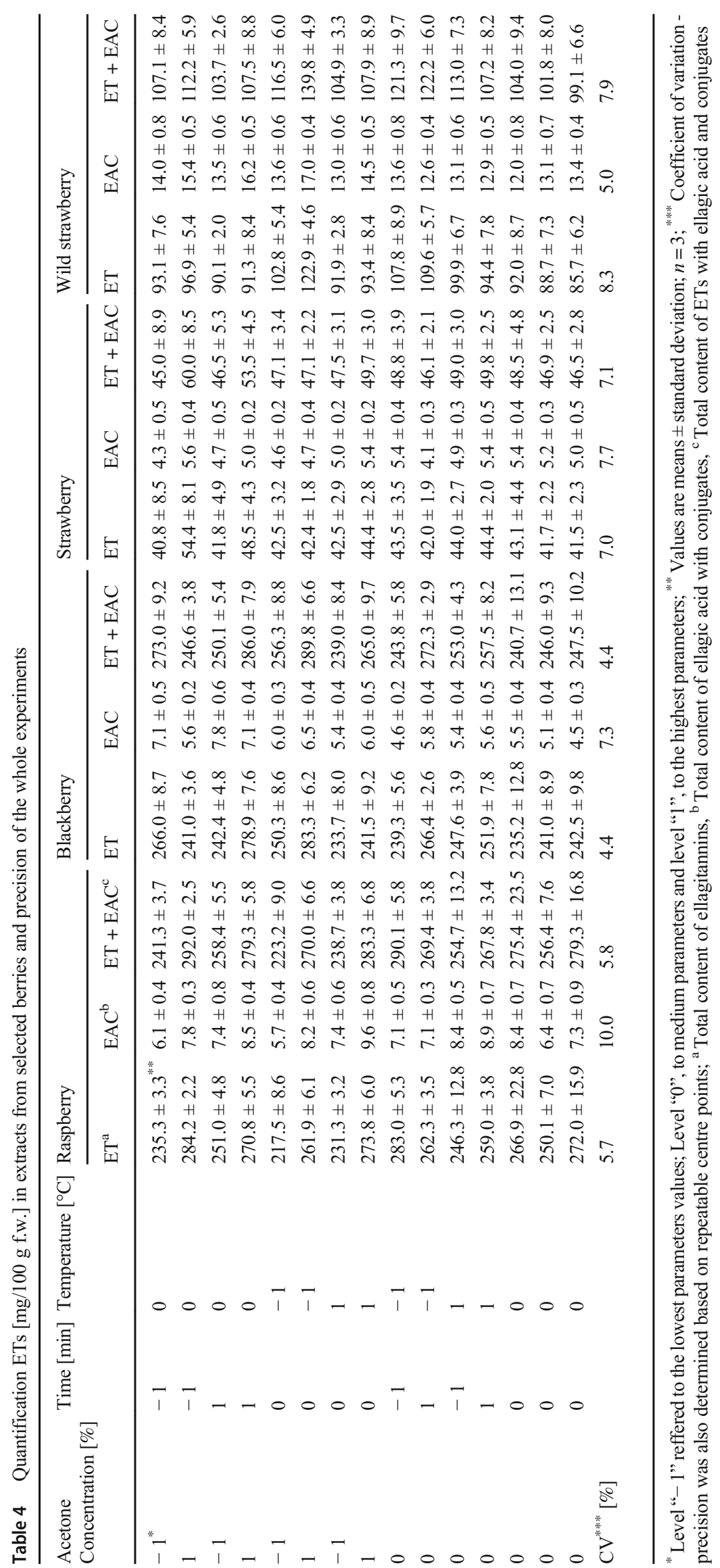


Table 5 Analysis of variance results of quadratic model

\begin{tabular}{|c|c|c|c|c|c|c|c|c|c|c|}
\hline Fruit & Factor & $\begin{array}{l}\text { Acetone } \\
\text { concentration (1) }\end{array}$ & Time (2) & $\begin{array}{l}\text { Temperature } \\
\text { (3) }\end{array}$ & $1 * 2$ & $1 * 3$ & $2 * 3$ & Lack of fit & Pure error & Total SS \\
\hline \multirow[t]{5}{*}{ Rubus idaeus L. } & $\mathrm{SS}^{\mathrm{a}}$ & 3321.1 & 183.1 & 176.2 & 222.0 & 1.2 & 285.6 & 608.2 & 300.2 & 5486.2 \\
\hline & $\mathrm{df}^{\mathrm{b}}$ & 1 & 1 & 1 & 1 & 1 & 1 & 3 & & \\
\hline & $\mathrm{MS}^{\mathrm{c}}$ & 3321.2 & 183.1 & 176.2 & 222.0 & 1.2 & 285.6 & 202.7 & 150.1 & \\
\hline & $\mathrm{F}^{\mathrm{d}}$ & 22.1 & 1.2 & 1.2 & 1.5 & 0.0 & 1.9 & 1.4 & 0.5 & \\
\hline & $\mathrm{p}^{\mathrm{e}}$ & 0.04 & 0.39 & 0.39 & 0.35 & 0.94 & 0.30 & 0.45 & & \\
\hline \multirow[t]{5}{*}{ Rubus fruticosus } & SS & 1175.1 & 470.0 & 387.0 & 970.3 & 14.1 & 144.0 & 513.1 & 25.5 & 3609.7 \\
\hline & $\mathrm{df}$ & 2 & 2 & 2 & 1 & 1 & 1 & 3 & 2 & 14 \\
\hline & MS & 587.6 & 235.0 & 193.3 & 970.3 & 14.1 & 144.0 & 171.0 & 12.8 & \\
\hline & $\mathrm{F}$ & 46.0 & 18.4 & 15.1 & 76.0 & 1.1 & 11.3 & 13.4 & & \\
\hline & $\mathrm{p}$ & 0.02 & 0.05 & 0.06 & 0.01 & 0.40 & 0.08 & 0.07 & & \\
\hline \multirow[t]{5}{*}{ Fragaria vesca } & SS & 154.9 & 21.1 & 557.8 & 0.4 & 103.0 & 11.2 & 90.1 & 12.1 & 1513.2 \\
\hline & $\mathrm{df}$ & 1 & 1 & 1 & 1 & 1 & 1 & 3 & 2 & 14 \\
\hline & MS & 154.9 & 21.1 & 557.8 & 0.4 & 103.0 & 11.2 & 30.0 & 6.0 & \\
\hline & $\mathrm{F}$ & 25.7 & 3.5 & 92.6 & 0.1 & 17.1 & 1.9 & 5.0 & & \\
\hline & $\mathrm{p}$ & 0.04 & 0.20 & 0.01 & 0.81 & 0.05 & 0.31 & 0.17 & & \\
\hline \multirow[t]{5}{*}{ Fragaria grandiflora } & SS & 83.7 & 24.9 & 10.7 & 16.0 & 1.2 & 3.1 & 50.3 & 2.2 & 192.9 \\
\hline & $\mathrm{df}$ & 2 & 2 & 2 & 1 & 1 & 1 & 3 & 2 & 14 \\
\hline & MS & 41.9 & 12.4 & 5.4 & 16.0 & 1.2 & 3.1 & 16.8 & 1.1 & \\
\hline & $\mathrm{F}$ & 37.4 & 11.1 & 4.8 & 14.3 & 1.1 & 2.7 & 15.0 & & \\
\hline & $\mathrm{p}$ & 0.03 & 0.08 & 0.17 & 0.06 & 0.41 & 0.24 & 0.06 & & \\
\hline
\end{tabular}

${ }^{\mathrm{a}}$ Sum of squares, ${ }^{\mathrm{b}}$ Degrees of freedom, ${ }^{\mathrm{c}}$ Mean square, ${ }^{\mathrm{d}} \mathrm{F}$ value, ${ }^{\mathrm{e}} \mathrm{p}$ value

efficiency of strawberry extraction, a three-stage extraction of the ellagitannins was used, supported by 15-min sonication (Klimczak and Król 2010). Taking into account the literature data, as well as the time and energy consumption of running the three-stage extraction, the duration of the process was set at 5-15 min.

For three out of the four tested fruits, the ETs concentration was comparable after a 5-min and 15-min sonication. For raspberries, wild strawberries, and strawberries, it was 270,110 , and $50 \mathrm{mg} / 100 \mathrm{~g}$ f.w. (5 min) and 260, 110, and $50 \mathrm{mg} / 100 \mathrm{~g} \mathrm{(15}$ min), respectively. The use of extended duration of sonication under the used extraction conditions has no analytical justification.

The extended duration of sonication was only important for blackberry, but the extraction should be carried out for $15 \mathrm{~min}$ to increase efficiency (within the tested range of 5-15 min). During the 5-min three-step extraction from blackberry fruit, $255 \mathrm{mg}$ of ETs per $100 \mathrm{~g}$ of fruit was extracted, while at 15 $\mathrm{min}$, this was $270 \mathrm{mg} / 100 \mathrm{~g}$. This may be due to the presence of a large amount of pigment compounds in brambles, which have the ability to bind to the ETs (Hager et al. 2008). The extended time of ETs extraction from blackberry can also be associated with the characteristic profile of this fruit, which includes a predominance of the high-molecular-weight compound lambertianin C (Hager et al. 2008; Sójka et al. 2016).

Duration of sonication is a factor influencing labor consumption and cost of extraction. Therefore, it was important to determine the optimal time for the most effective isolation of ETs from plant material.

\section{Interactions}

The values of ETs concentrations for individual factors and interactions occurring between them were determined based on an analysis of variance (Tables 4 and 5).

Charts 1-4 (Figs. 6, 7, 8, and 9) show the interactions of factors affecting the efficiency of ETs extraction from the tested fruits. In the case of raspberry, the highest ETs concentration was
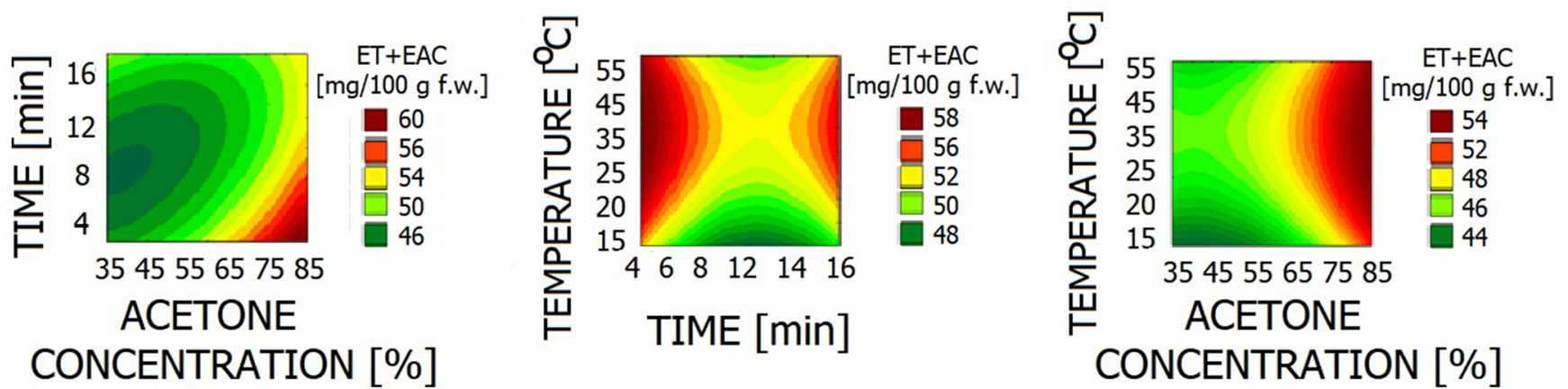

Fig. 8 Plane response plots - dependencies between tested parameters and sum of ETs from strawberry fruit 

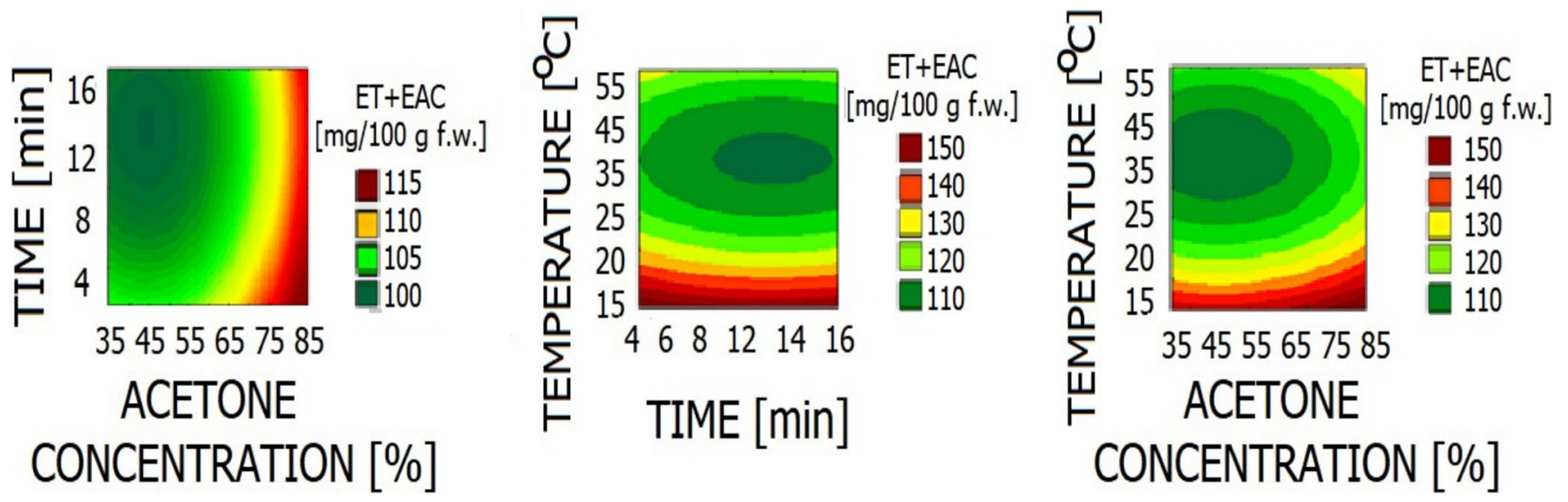

Fig. 9 Plane response plots - dependencies between tested parameters and sum of ETs from wild strawberry fruit

recorded in the highest acetone concentration tested (80\%), regardless of the duration of sonication and extraction temperature. The dependence of time and temperature shows that the highest efficiency was achieved using lower temperatures and shorter duration of sonication. Analysis of the interaction of duration and temperature of extraction of ETs from the strawberry fruit indicates that, regardless of the temperature, in a short time the highest efficiency of ETs separation was achieved. The extraction of ETs from wild strawberry looked similar, but raising the extraction temperature produced a lower concentration of the ellagitannins.

The content of ellagitannins with ellagic acid differed in the tested fruits depending on the extraction parameters used. The Pareto diagrams (Fig. 10) and the analysis of the ANOVA variance confirm that acetone concentration was crucial for all fruits $(p<0.05$ for raspberries, strawberries, blackberries, and wild strawberries). It was the main and most important factor affecting the efficiency of ETs extraction. Statistical analysis showed that in the case of ET extraction from three out of the four tested fruits, regardless of the length of process and temperature, the concentration of acidified acetone solution had the greatest influence.

For three out of the four tested fruits, the use of extended duration of sonication at lower acetone concentrations was not more effective compared to the use of higher concentration and shorter duration of sonication. The quantities of ellagitannins extracted during the three-stage 5-min sonication were similar to the effects of 15-min sonication. The obtained results are consistent with literature reports, according to which a longer extraction time did not contribute to more efficient isolation of polyphenols from plant tissue (da Silva Pinto et al. 2008). In addition, a shorter duration of sonication reduces the risk of tannin degradation (Mane et al. 2007).

In the case of blackberry, the interaction of acetone with time can be observed. For the longest duration of sonication (15 min) and with the highest concentration of acetone in the studied range $(80 \%)$, the highest concentration of ellagitannins was reported to be $286 \mathrm{mg} / 100 \mathrm{~g}$. Perhaps this is due to the fact that the blackberry contains a large number of anthocyanins that bind the ellagitannins, thus hindering their

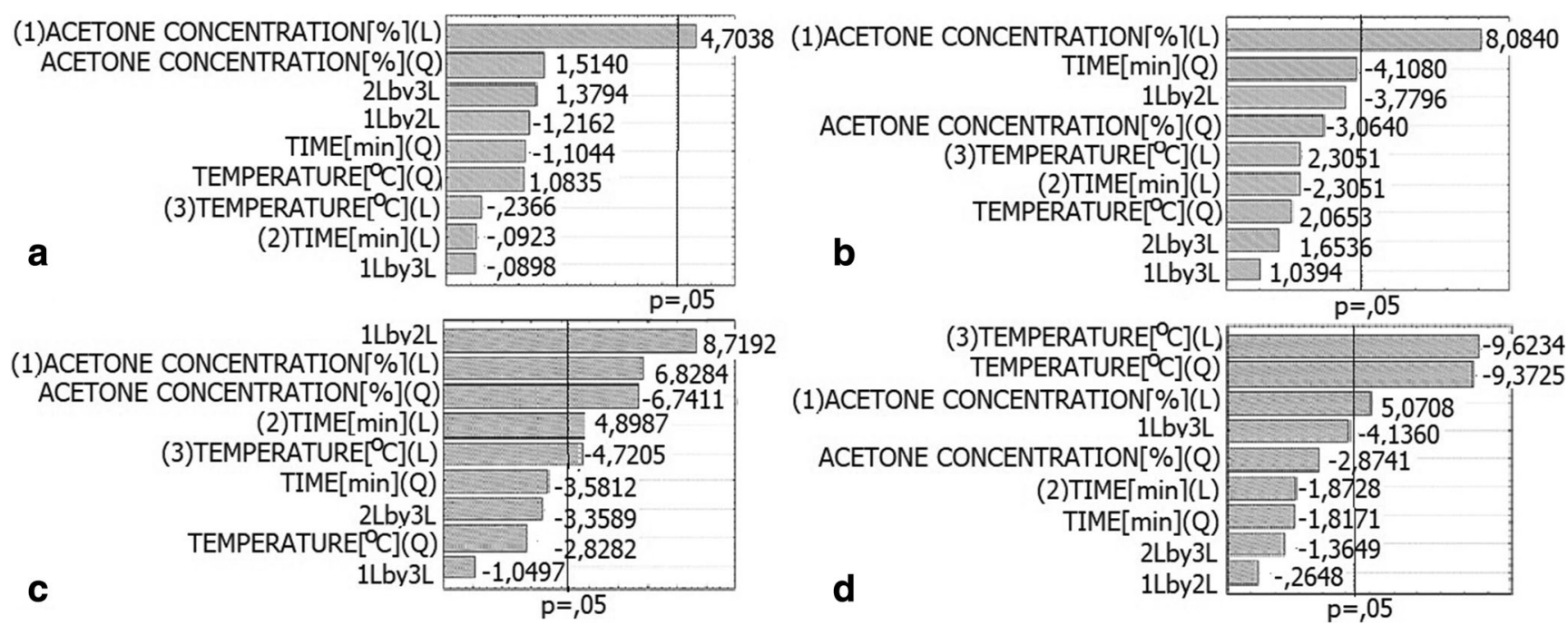

Fig. 10 Pareto diagram showing the influence of individual parameters or their interaction on the extraction process of ETs from fruits: a raspberry, $\mathbf{b}$ strawberry, c blackberry, and d wild strawberry 
Table 6 Regression coefficient $R^{2}$ and experimental and predictable values for the selected model for three-step extraction of ETs in conditions enabling the best extraction of ETs (in the examined range)

\begin{tabular}{lllllll}
\hline Fruit & $\begin{array}{l}\text { Acetone } \\
\text { concentration } \\
{[\%]}\end{array}$ & $\begin{array}{l}\text { Temperature } \\
{\left[{ }^{\circ} \mathrm{C}\right]}\end{array}$ & $\begin{array}{l}\text { Time } \\
{[\mathrm{min}]}\end{array}$ & $R^{2}$ & $\begin{array}{l}\text { Predicted } \\
\text { value } \\
\text { ETs [mg/100 g f.w. }]\end{array}$ & $\begin{array}{l}\text { Observed } \\
\text { value }\end{array}$ \\
\hline Raspberry & 80 & 20 & 5 & 0.834 & 299.6 & 290.0 \\
Blackberry & 80 & 20 & 15 & 0.851 & 259.6 & 262.6 \\
Strawberry & 80 & 20 & 5 & 0.728 & 56.1 & 58.3 \\
Wild & 80 & 20 & 5 & 0.933 & 134.0 & 130.3 \\
$\quad$ strawberry & & & & & & \\
\hline
\end{tabular}

extraction (Hager et al. 2008). The temperature turned out to be a negligible factor $(p>0.05)$.

\section{Selection of the Best Conditions for Extraction of ETs}

Based on the response surface methodology and the analysis of variance, the best three-stage ETs extraction model supported by sonication (with the initial homogenisation step) from selected fruit of the Rosaceae family (in the examined parameters) was determined (Table 6). In order to check the correctness of the model, the extraction was carried out under optimal conditions, and the experimental results were compared with the predicted results.

The obtained sum values of ETs in the selected model for individual fruits are practically the same, which confirms the reliability of the selected models. The high regression coefficient (0.7-0.9) confirms that the variability of the ellagitannin concentration is well described by the presented model.

The paper also indicates the maximum values of the main ellagitannins, characteristic for the tested fruits. According to literature data, the profile of the fruits of the Rosaceae family is shaped in the following way: in raspberry and blackberry, the highest concentations are sanguiin H-6 and lambertianin $\mathrm{C}$, while in the wild strawberry and strawberry-agrimoniin (29 and $23 \mathrm{mg} / 100 \mathrm{~g}$ f.w., respectively) (Hager et al. 2008; Bubba et al. 2012; Aaby et al. 2005; Sójka et al. 2016; Klimczak and Król 2010). In wild strawberry, unidentified ellagitannins were also noted, which accounted for more than $50 \%$ of the total ETs ( $60 \mathrm{mg} / 100 \mathrm{~g}$ of fresh weight). In studies carried out to date, it was suggested that this may be an unknown ellagic acid trimer derivative (Bubba et al. 2012).

\section{Conclusions}

Extraction of ETs from the fruits matrix is an important element in their correctly identification and quantification. The research clearly showed that homogenisation of fruits is an important element, which allows over $20 \%$ more ETs to be obtained and significantly shortens the extraction time. The crushing of the test fruits using a cryogenic mill is therefore not an extensive pre-treatment process.
The extraction can be assisted both by shaking and sonication, resulting in similar concentration of ETs in the extract. The difference in ETs extraction efficiency appeared in the combined techniques: homogenisation plus sonication and homogenisation plus shaking. Higher concentration of extracted ETs was observed for sonication plus homogenisation. Using the RSM, an appropriate ETs extraction model was determined for the four fruits of the Rosaceae family. In all cases, the most important factor was the concentration of acetone, while for the blackberry, there was an interaction with the duration of sonication. For raspberry, wild strawberry, and strawberry, the extraction parameters (temperature, duration of sonication, acetone concentration) were set at $20^{\circ} \mathrm{C}, 5$ min, and $80 \%$, respectively. In the case of blackberry, the duration of sonication was changed, which in the best model in tested parameters was $15 \mathrm{~min}$.

Selection of appropriate extraction conditions for ETs allows their quick and effective separation from the tested fruits. Using this method, the optimum efficiency of the extraction system can be developed. This allows the ETs extraction efficiency to be increased, as well as reducing the time and costs of the entire process.

\section{Compliance with Ethical Standards}

Conflict of Interest Agnieszka Milczarek declares that she has no conflict of interest. Michał Sójka declares that he has no conflict of interest. Robert Klewicki declares that he has no conflict of interest.

Ethical Approval This article does not contain any studies with human participants or animals performed by any of the authors.

Informed Consent Not applicable.

Open Access This article is licensed under a Creative Commons Attribution 4.0 International License, which permits use, sharing, adaptation, distribution and reproduction in any medium or format, as long as you give appropriate credit to the original author(s) and the source, provide a link to the Creative Commons licence, and indicate if changes were made. The images or other third party material in this article are included in the article's Creative Commons licence, unless indicated otherwise in a credit line to the material. If material is not included in the article's Creative Commons licence and your intended use is not permitted by statutory regulation or exceeds the permitted use, you will need to obtain permission directly from the copyright holder. To view a copy of this licence, visit http://creativecommons.org/licenses/by/4.0/. 


\section{References}

Aaby K, Skrede G, Wrolstad RE (2005) Phenolic composition and antioxidant activities in flesh and achenes of strawberries (Fragaria ananassa). J Agric Food Chem 53:4032-4040

Akowuah GA, Mariam A, Chin JH (2009) The effect of extraction temperature on total phenols and antioxidant activity of Gynura procumbens Leaf. Phcog Mag 5:81-85

Baqueiro-Pena I, Guerrero-Beltran JA (2017) Physicochemical and antioxidant characterization of Justicia spicigera. Food Chem 218:305312

Bashi DS, Mortazavi SA, Rezaei K, Rajaei A, Karimkhani MM (2012) Optimization of ultrasound-assisted extraction of phenolic compounds from yarrow (Achillea beibrestinii) by response surface methodology. Food Sci Biotechnol 21(4):1005-1011

Beekwilder J, Jonker H, Meesters P (2005) Antioxidants in raspberry: online analysis links antioxidant activity to a diversity of individual metabolites. J Agric Food Chem 53(9):3313-3320

Bezerra MA, Santelli RE, Oliveira EP, Silveira Villar L, Escaleira LA (2008) Response surface methodology (RSM) as a tool for optimization in analytical chemistry. Talanta 76:965-977

Boyles MJ, Wrolstad RE (1993) Anthocyanin composition of red raspberry juice: influences of cultivar processing and environmental factors. J Food Sci 58:1135-1141

Bubba M, Checchini L, Chiuminatto U, Doumett S, Fibbi D, Giordani E (2012) Liquid chromatographic/electrospray ionization tandem mass spectrometric study of polyphenolic composition of four cultivars of Fragaria vesca L. berries and their comparative evaluation. J Mass Spectrom 47:1207-1220

Chandrapala J, Oliver CM, Kentish S, Ashokkumar M (2013) Use of power ultrasound to improve extraction and modify phase transitions in food processing. Food Rev Int 29(1):67-91

Chira K, Teissedre P-L (2013) Extraction of oak volatiles and ellagitannins compounds and sensory profile of wine aged with French winewoods subjected to different toasting methods: behaviour during storage. Food Chem 140:168-177

Chirinos R, Rogez H, Campos D, Pedreschi R, Larondelle Y (2007) Optimisation of extraction conditions of antioxidant phenolic compounds from mashua (Tropaeolum tuberosum Ruíz \& Pavón) tubers. Sep Purif Technol 5:217-225

Corthout J, Peiters LA, Claeys M, Vanden Berghe DA, Vlietinck AJ (1991) Antiviral ellagitannins from Spondias mombin. Phytochemistry 30:1129-1130

da Silva Pinto M, Lajolo FM, Genovese MI (2008) Bioactive compounds and quantification of total ellagic acid in strawberries (Fragaria $x$ ananassa Duch.). Food Chem 107:1629-1635

Dai J, Mumper RJ (2010) Plant phenolics: extraction, analysis and their antioxidant and anticancer properties. Molecules 15:7313-7352

Davidov-Pardo G, Arozarena MRI, Marin-Arroyo MR (2011) Stability of polyphenolic extracts from grape seeds after thermal treatments. Eur Food Res Technol 232:211-220

Del Rio D, Borges G, Crozier A (2010) Berry flavonoids and phenolics: bioavailability and evidence of protective effects. Br J Nutr 104: S67-S90

Dias MI, Barros L, Oliveira BPP, Santos-Buelga C, Ferreira I (2015) Phenolic profile and antioxidant properties of commercial and wild Fragaria vesca L. roots: a comparison between hydromethanolic and aqueous extracts. Ind Crop Prod 63:125-132

Feldman KS, Iyer MR, Liu Y (2003) Ellagitannin chemistry. Studies on the stability and reactivity of 2,4-HHDP-Containing glucopyranose systems. J Org Chem 68:7433-7438

Galvan d'Alessandro L, Kriaa K, Nikova I, Dimitrov K (2012) Ultrasound assisted extraction of polyphenols from black chokeberry. Sep Purif Technol 93:42-47
Garcia-Marquez E, Roman-Guerrero A, Perez-Alonso C, Cruz-Sosa F, Jimenez-Alvarado R, Vernon-Carter EJ (2012) Effect of solventtemperature extraction conditions on the initial antioxidant activity and total phenolic content of muitle extracts and their decay upon storage at different $\mathrm{pH}$. Revista Mexicana de Ingenieria Quimica 11: $1-10$

Gasperotti M, Masuero D, Vrhovsek U, Guella G, Mattivi F (2010) Profiling and accurate quantification of Rubus ellagitannins and ellagic acid conjugates using direct UPLC-Q-TOF HDMS and HPLCDAD analysis. J Agric Food Chem 58:4602-4616

Guerrero S, Lopez-Malo A, Alzamora SM (2001) Effect of ultrasound on the survival of Saccharomyces cerevisiae: Influence of temperature, pH and amplitude. Innov Food Sci Emerg Technol 2:31-39

Hager TJ, Howard LR, Liyanage R, Lay JO, Prior RL (2008) Ellagitannin composition of blackberry as determined by HPLC-ESIMS and MALDI-TOF-MS. J Agric Food Chem 56:661-669

Hakkinen SH, Torronen AR (2000) Content of flavonols and selected phenolic acids in strawberries and Vaccinium species: influence of cultivar, cultivation site and technique. Food Res Int 33:517-524

Heinonen M, Lehtonen PJ, Hopia AI (1998) Antioxidant activity of berry and fruit wines and liquors. J Agric Food Chem 46(1):25-31

Japon-Lujan R, Luque-Rodriguez JM, Luque de Castro MD (2006) Dynamic ultrasound-assisted extraction of oleuropein and related biophenols from olive leaves. J Chromatogr 1108:76-82

Kahkonen M, Kylli P, Ollilainen V, Salminen JP, Heinonen M (2012) Antioxidant activity of isolated ellagitannins from red raspberries and cloudberries. J Agric Food Chem 60:1167-1174

Khan MK, Abert-Vian M, Fabiano-Tixier AS, Dangles O, Chemat F (2010) Ultrasound-assisted extraction of polyphenols (flavanone glycosides) from orange (Citrus sinensis L.) peel. Food Chem 119(2):851-858

Klimczak E, Król B (2010) Determination of different forms of ellagic acid acid in by-products of strawberry processing. [Oznaczanie zawartości różnych form kwasu elagowego w ubocznych produktach przerobu truskawek]. Żywność Nauka Technologia Jakość 4(71):81-94

Klimczak E, Rozpara E, Król B (2011) Distribution of ellagitannins in juice, flesh and achenes as additional criterion for optimal utilization of strawberries. [Rozmieszczenie elagotanin w soku, miązszu i nasionach jako dodatkowe kryterium optymalnego zagospodarowania truskawek]. Żywność Nauka Technologia Jakość 6(79):142-154

Larrosa M, Tomas-Barberan FA, Espin JC (2006) The dietary hydrolysable tannin punicalagin releases ellagic acid that induces apoptosis in human colon adenocarcinoma Caco-2 cells by using the mitochondrial pathway. J Nutr Biochem 17(1):611-625

Larrosa M, Garcia-Conesa MT, Espin JC, Tomas-Barberan FA (2010) Ellagitannins, ellagic acid and vascular health. Mol Asp Med 31: 513-539

Lee WC, Yusof S, Hamid NSA, Baharin BS (2006) Optimizing conditions for hot water extraction of banana juice using response surface methodology (RSM). J Food Eng 75(4):473-479

Lei Z, Jervis J, Helm RF (2001) Use of methanolysis for the determination of total ellagic and gallic acid contents of wood and food products. J Agric Food Chem 49:1165-1168

Lekha PK, Lonsane BK (1997) Production and application of tannin acyl hydrolase: state of the art. Adv Appl Microbiol 44:215-260

Liu FF, Ang CYW, Springer D (2000) Optimization of extraction conditions for active components in Hypericum perforatum using surface methodology. J Agric Food Chem 48:3364-3371

Ma YQ, Ye XQ, Fang ZX, Chen JC, Xu GH, Liu DH (2008) Phenolic compounds and antioxidant activity of extracts from ultrasonic treatment of satsuma mandarin (Citrus unshiu Marc.) peels. J Agric Food Chem 56:5682-5690

Mane C, Souqet M, Olle D, Verries C, Veran F, Mazeromeln G, Cheynier V, Fulcrand H (2007) Optimisation of simultaneous flavonol, 
phenolic acid and anthocyjanin extractions from grapes using and experimental design: application to the characterisation of champagne grape varietes. J Agric Food Chem 55:7224-7233

Medina-Torres N, Ayora-Talavera T, Espinosa-Andrews H, SánchezContreras A, Pacheco N (2017) Ultrasound assisted extraction for the recovery of phenolic compounds from vegetable sources. Agronomy 7(3):47

Mullen W, McGinn J, Lean MEJ, MacLean MR, Gardner P, Duthie GG, Crozier A (2002) Ellagitannins, flavonoids and other phenolics in red raspberries and their contribution to antioxidant capacity and vasorelaxation properties. J Agric Food Chem 50:5191-5196

Niemetz R, Gross GG (2005) Enzymology of gallotannin and ellagitannin biosynthesis. Phytochemistry 66(17):2001-2011

Okuda T, Ito H (2011) Tannins of constant structure in medicinal and food plants - hydrolyzable tannins and polyphenols related to tannins. Molecules 16:2191-2217

Okuda T, Yoshida T, Hatano T, Iwasaki M, Kubo M, Orime T, Yoshizaki M, Naruhashi N (1992) Hydrolysable tannins as chemotaxonomic markers in the Rosaceae. Phytochemistry 31(9):3091-3096

Oszmiański J, Wojdyło A (2009) Comparative study of phenolic content and antioxidant activity of strawberry puree, clear and cloudy juices. Eur Food Res Technol 228:623-631

Perez-Jimenez J, Fezeu L, Touvier M, Arnault N, Manach C, Hercberg S, Galan P, Scalbert A (2011) Dietary intake of 337 polyphenols in French adults. Am J Clin Nutr 93:1220-1228

Popko H (1981) Podstawy teorii homogenizacji. Materiały I Krajowej Konferencji Uczelniano-Przemysłowej pt.: „Homogenizacja w przemyśle spożywczym”, zorganizowanej przez Zakład Maszyn Spożywczych Politechniki Lubelskiej w czerwcu 1981 r., Wyd. Naukowe Politechniki Lubelskiej, Lublin

Rao AV, Snyder DM (2010) Raspberries and human health: a review. J Agric Food Chem 58:3871-3883

Ross HA, McDougall GJ, Stewart D (2007) Antiproliferative activity is predominantly associated with ellagitannins in raspberry extracts. Phytochemistry 68:218-228

Salminen JP (2003) Effects of sample drying and storage, and choice of extraction solvent and analysis method on the yield of birch leaf hydrolysable tannins. J Chem Ecol 29:1289-1305

Sangiovanni E, Vrhovsek U, Rossoni G, Colombo E, Brunelli C, Brembati L, Trivulzio S, Gasperotti M, Mattivi F, Bosisio E, Dell'Agli M (2013)
Ellagitannins from Rubus berries for the control of gastric inflammation: in vitro and in vivo studies. PLoS One 8(8):e71762

Seeram NP, Adams LS, Zhang Y, Lee R, Sand D, Scheuller HS, Heber D (2006) Blackberry, black raspberry, blueberry, cranberry, red raspberry, and strawberry extracts inhibit growth and stimulate apoptosis of human cancer cells in vitro. J Agric Food Chem 54:9329-9339

Siriwoharn T, Wrolstad RE (2004) Polyphenolic composition of Marion and evergreen blackberries. J Food Sci 69(4):233-240

Sójka M, Macierzyński J, Zaweracz W, Buczek M (2016) Transfer and mass balance of ellagitannins, anthocyanins, flavan-3- ols, and flavonols during the processing of red raspberries (Rubus idaeus L.) to juice. J Agric Food Chem 64:5549-5563

Sójka M, Janowski M, Grzelak-Błaszczyk K (2019) Stability and transformations of raspberry (Rubus idaeus L.) ellagitannins in aqueous solutions. Eur Food Res Technol 245:1113-1122

Tanaka T, Tachibana H, Nonaka G-I, Nishioka I, Hsu F-L, Kohda H, Tanaka O (1993) Tannins and related compounds. CXXII. New dimeric, trimeric and tetrameric ellagitannins, lambertianins A-D, from Rubus lambertianus. Chem Pharm Bull 41:1214-1220

Vilkhu K, Mawson R, Simons L, Bates D (2007) Applications and opportunities for ultrasound assisted extraction in the food industry $-\mathrm{a}$ review. Innov Food Sci Emerg Technol 9:161-169

Vrhovsek U, Guella G, Gasperotti M, Pojer E, Zancato M, Mattivi F (2012) Clarifying the identity of the main ellagitannin in the fruit of the strawberry, Fragaria vesca and Fragaria ananassa Duch. J Agric Food Chem 60:2507-2516

Wada L, Ou B (2002) Antioxidant activity and phenolic content of Oregon caneberries. J Agric Food Chem 50:3495-3500

Wu X, Prior RL (2005) Systematic identification and characterization of anthocyanins by HPLC-ESI-MS/MS in common foods in the United States: fruits and berries. J Agric Food Chem 53:2589-2599

Zhang Z-S, Li D, Wang LJ, Ozkan N, Chen XD, Mao Z-H, Yang H-Z (2007) Optimisation of ethanol - water extraction of lignans from flaxseed. J Separation Purif Technol 57:17-24

Publisher's Note Springer Nature remains neutral with regard to jurisdictional claims in published maps and institutional affiliations. 